\title{
Design of Counter Beam Tunnel Lights for CIE $88: 2004$ Regulation in Threshold Zone
}

\author{
Ming-Jui Chen, ${ }^{1}$ Hien-Thanh Le $\mathbb{D}^{1,2}$ Lanh-Thanh Le ${ }^{1}{ }^{1,2}$ Wei-Hsiung Tseng, ${ }^{3}$ \\ Wei-Yang Lee, ${ }^{1}$ Si-Yuan Chen, ${ }^{1}$ Sheng-Yen Chen, ${ }^{1}$ Hsing-Yuan Liao, ${ }^{1}$ Yung-Cheng Li, ${ }^{4}$ \\ and Hsiao-Yi Lee $\mathbb{D}^{1,5}$ \\ ${ }^{1}$ Department of Electrical Engineering, National Kaohsiung University of Science and Technology, Kaohsiung 80778, Taiwan \\ ${ }^{2}$ Department of Technology, Dong Nai Technology University, Bien Hoa 830000, Dong Nai, Vietnam \\ ${ }^{3}$ Department of Aviation \& Communication Electronics, Air Force Institute of Technology, Kaohsiung City 820, Taiwan \\ ${ }^{4}$ Department of Materials Science and Engineering, National Tsing Hua University, No. 101, Section 2, Kuang-Fu Road, \\ Hsinchu 30013, Taiwan \\ ${ }^{5}$ Department of Graduate Institute of Clinical Medicine, Kaohsiung Medical University, Kaohsiung 807, Taiwan
}

Correspondence should be addressed to Hsiao-Yi Lee; leehy@nkust.edu.tw

Received 5 December 2019; Revised 27 February 2020; Accepted 3 March 2020; Published 30 March 2020

Academic Editor: Sulaiman W. Harun

Copyright (C) 2020 Ming-Jui Chen et al. This is an open access article distributed under the Creative Commons Attribution License, which permits unrestricted use, distribution, and reproduction in any medium, provided the original work is properly cited.

\begin{abstract}
To enhance driving safety, a counter beam light is proposed to meet CIE (International Commission on Illumination) specifications for tunnel lighting. The proposed new counter beam light (CBL) acts as a qualified counter beam light to help tunnel road lighting meet the CIE 88:2004 regulation standard in the threshold zone in both simulation and in practice. Through appropriate arrangements of the counter beam light and conventional fluorescent lights on the tunnel ceiling, we demonstrate that road tunnel lighting meeting CIE 88:2004 standards can be accomplished. Based on LiteStar four-dimensional simulation, the source file created through the measurement of the proposed CBL prototype achieved an average road surface brightness of $121 \mathrm{~cd} / \mathrm{m}^{2}$, which is greater than the minimum regulation level of $105 \mathrm{~cd} / \mathrm{m}^{2}$, a brightness uniformity of 0.88 (minimum regulation level of 0.4 ), longitudinal brightness uniformity of 0.98 (minimum regulation level of 0.6 ), a glare factor of $4.41 \%$ (maximum level of $15 \%$ ), and a contrast revealing coefficient of 1.08 , which is above the 0.6 minimum level in the threshold zone.
\end{abstract}

\section{Introduction}

The main objective of tunnel lighting is to allow traffic to enter, pass through, and exit the enclosed section of the tunnel safely [1-4]. These aims are achieved through the adequate illumination of the tunnel interior, which allows drivers to quickly adjust to the light and identify possible obstacles on the road in tunnels. The threshold zone is the first zone within the actual tunnel that extends for the same length as the stopping sight distance for the design [5-8]. When using the $L_{20}$ method, the target luminance level $L_{\text {th }}$ (threshold zone luminance) for this zone is derived from the portal luminance $\left(L_{20}\right)$ factored by the $k$ value associated with the class of tunnel $[9,10,11]$. This level is maintained at
$100 \%$ for the first half of the threshold zone and reduces to $40 \%$ by the end of the zone. The $k$ factor is inversely proportional to the contrast revealing coefficient $q_{c}$, so if $q_{c}$ can be elevated, the required $L_{\text {th }}$ can be decreased, which can provide the necessary lighting conditions for the tunnel road while decreasing the consumed electrical power and the maintenance cost of lighting. However, since the new CIE $88: 2004$ regulation was published, updating tunnel lights to achieve a high contrast revealing coefficient is rarely performed, so few commercial tunnel lights are qualified as counter beam lights $[12,13,7]$. Many newly built tunnels, such as the Conway Eastbound tunnel on the A55 in the U.K., adopt symmetrical lights in threshold zone, guaranteeing a $q_{c}$ of only more than $0.2[14,15,16]$. To decrease the 
$L_{\text {th }}$ level and follow the CIE 88:2004 regulation and as counter beam lights can guarantee a $q_{\mathrm{c}}$ higher than 0.6 , they are always considered for tunnel lighting.

In this study, a freeform surfaced luminaire is proposed to handle $400 \mathrm{~W}$ high-pressured sodium lamps to act as the counterbeam lights for CIE 88:2004 tunnel road lighting. The efficiency and lifespan of white light emitting diodes (LEDs) have improved, but the golden light of high-pressured sodium lamps has the specific advantage of high fog permeability and low insect attraction, which increase driver safety in the threshold and exit zones, where the dangerous black-hole effect or white hole effect need to be addressed. As a result, lights with high-pressured sodium lamps are still commonly used in the entrances and exits of tunnels. The proposed counterbeam light was prototyped and its intensity distribution was measured using a goniophotometer to obtain its far field data. By importing the data into tunnel lighting analysis software, we found that the counter beam light combined with conventional fluorescent lights can meet tunnel road lighting CIE 88:2004 regulations in the threshold zone, yielding an average road surface luminance $L_{\mathrm{av}}$ of $130 \mathrm{~cd} / \mathrm{m}^{2}$, which is greater than the minimum regulation level of $105 \mathrm{~cd} / \mathrm{m}^{2}$, a luminance uniformity $U_{\mathrm{o}}$ of $0.89>0.4$ (minimum regulation level), a longitudinal luminance uniformity $U_{\mathrm{L}}$ of $0.99>0.6$ (minimum regulation level), a glare factor $T_{\mathrm{I}}$ of $5.5 \%<15 \%$ (maximum level), and a contrast display factor $q_{\mathrm{c}}$ of $1.24>0.6$ (minimum level) in the threshold zone.

\section{Principles}

The major difference between tunnel lighting and conventional road lighting is in the need for lighting by day $[17,18,19]$. A driver needs to be able to see a certain distance ahead so that if an unexpected hazard appears, the driver can react and stop within that distance. When this distance extends into a tunnel, the lighting level inside should be sufficiently high to maintain visibility. If the lighting level is not high, the driver will be unable to see into the tunnel, which is called the black-hole effect. During approach and entry into a tunnel, drivers' eyes adapt to the darker surroundings. This adaptation is a continuous process, so the further into the tunnel the driver travels, providing the tunnel is of sufficient length, the lighting level may be steadily reduced until it reaches a constant level in the tunnel interior zone. On emerging from a tunnel into daylight, the eye adapts far more quickly to the higher luminance level. The lighting of a tunnel should be sufficient to prevent the black-hole effect when a driver is unable to see into the tunnel. As such, tunnel road lighting must satisfy some stringent requirements, such as the CIE $88: 2004$ regulation.

In order to avoid encountering the black-hole effect when approaching the portal of a tunnel and to help drivers adapt to the lighting environment in a tunnel, there are five lighting zones distributed throughout a tunnel such as access zone, threshold zone, transition zone, interior zone, and exit zone. The transition zone is given by

$$
L_{t r}=L_{t h} \times(1 \cdot 9+t)^{-1,4},
$$

where $L_{t r}$ is the road surface luminance in the transition zone, $L_{t h}$ is the road surface luminance in the threshold zone, and $t$ is the driving time in seconds. The necessary driving time in the transition zone $t_{\text {tr }}$ is then given by

$$
\mathrm{t}_{\mathrm{tr}}=\left(\frac{L_{\text {in }}}{L_{t h}}\right)^{-0.714}-1.9 \text { seconds. }
$$

The threshold zone is the first inner region encountered when entering a tunnel and where the black-hole effect critically dominates. Based on the CIE $88: 2004$ regulation, the threshold zone luminance is usually set to be higher than $L_{\text {th. }}$ :

$$
L_{t h}=\frac{L_{m}}{1 / C_{m}\left(\rho / \pi \cdot q_{c}-1\right)-1},
$$

where $L_{m}=\left(\tau_{\mathrm{ws}} \times L_{\mathrm{atm}}+L_{\mathrm{ws}}+L_{\mathrm{seq}}\right) /\left(\tau_{\mathrm{ws}} \times \tau_{\mathrm{atm}}\right), C_{\mathrm{m}}$ is the minimum required perceived contrast $(-0.28), \rho$ is the reflectance factor of the target $(0.2), \tau_{\mathrm{ws}}$ is the windscreen transmission factor (0.8), $\tau_{\text {atm }}$ is the atmosphere transmission factor (1.0), $L_{\mathrm{seq}}=5.1 \times 10^{-4} \Sigma \mathrm{L}_{\mathrm{ije}}$ with $L_{i j e}=\left(\tau_{\mathrm{ws}} \times\right.$ $\left.L_{i j}\right)+\mathrm{L}_{\mathrm{ws}}$ is the equivalent veiling luminance, $L_{\mathrm{ije}}$ is the luminance of each section in front of the eye $\left(\mathrm{cd} / \mathrm{m}^{2}\right), L_{\mathrm{ij}}$ is the average luminance of each section measured outside the car in front of the windscreen $\left(\mathrm{cd} / \mathrm{m}^{2}\right), L_{\text {atm }}$ is the atmospheric veiling luminance $\left(200 \mathrm{~cd} / \mathrm{m}^{2}\right.$, medium veiling level), $L_{\mathrm{ws}}$ is the windscreen veiling luminance $\left(100 \mathrm{~cd} / \mathrm{m}^{2}\right.$, medium veiling level), and $q_{c}$ is the contrast revealing coefficient ( $\geq 0.2$ for symmetrical light systems or $\geq 0.6$ for counterbeam light systems).

Based on the Holladay-Stiles formula, the equivalent veiling luminance $L_{\text {seq }}$ can be determined busing a graphical method to identify $L_{t h}$. The equivalent veiling luminance $L_{\text {seq }}$ is found from $L_{\text {seq }}=5.1 \times 10^{-4} \sum L_{i j e}$ with $L_{i j e}=\left(\tau_{\mathrm{ws}} \times\right.$ $\left.L_{i j}\right)+L_{\mathrm{ws}}$. The contrast revealing coefficient $\left(q_{\mathrm{c}}=L / \mathrm{E}_{\mathrm{v}}\right)$ is the ratio between the luminance of the road surface and the vertical illuminance $\mathrm{Ev}$ at a specific location in the tunnel. $C_{\mathrm{m}}$ is the minimum required perceived contrast, where $28 \%$ is recommended. This contrast is mostly negative (for any $q_{\mathrm{c}}$ greater than 0.06 with a reflectance factor of the target equal to 0.2 ). To determine the threshold road luminance, the designer should start from the standardized figures for the contrast revealing coefficient (either 0.2 for symmetrical light systems or 0.6 for counterbeam light systems). To identify a more precise threshold luminance value, an iterative process is necessary. After selecting an initial estimated figure for the average $q_{c}$ of the installation and calculating the correlated $L_{\mathrm{th}}$, the real average $q_{\mathrm{c}}$ of the installation may need to be calculated to verify initial assumptions. In general, the atmospheric transmissivity $\left(\tau_{\text {atm }}\right)$ for design purposes is assumed to be 1.0 and the transmission factor for the windscreen $\left(\tau_{\mathrm{ws}}\right)$ is assumed to be 0.8 . Disability glare reduces visibility and shall be minimized. If disability glare is controlled under tunnel lighting conditions, then discomfort glare will also be controlled. Disability glare effects shall be quantified by means of threshold increment $\left(T_{\mathrm{I}}\right)$. Good uniformity of luminance must be provided on the road surface. The recommended minimum to the average value of the luminance on the road surface in 
clean conditions of the tunnel is 0.4. A longitudinal uniformity of 0.6 along the center of each lane is recommended for the road. It is recommended that these values are independently reached on the length of the step. The values of 0.4 and 0.6 are those corresponding to the values for normal road lighting provided in CIE 115-1995 [7, 13].

Asymmetrical directional lighting, such as counterbeam and probeam lighting, distributes patterns in only one direction, either with or against traffic. Counterbeam lighting directs the maximum optical intensity against traffic along the driver's line of vision, creating a high negative contrast. By minimizing glare, drivers can clearly see the contours of the vehicle ahead. Probeam lighting directs the maximum candlelight with the traffic away from the driver, providing high object luminance and low road luminance, creating a positive contrast. This system operates by minimizing luminaire glare and increasing distance visibility.

\section{Experimental Setup and Results}

The tunnel for the study is located in the eastern part of Taiwan, and its entrance is shown in Figure 1. The geometry of the tunnel is shown in Figure 2, and its details are as follows: motorway tunnel, 2 unidirectional bores; two traffic lanes, $3.75 \mathrm{~m}$ each; total width, $10 \mathrm{~m}$; ceiling height, $8.05 \mathrm{~m}$; and length of tunnel, $>500 \mathrm{~m}$. The tunnel orientation is south to north.

The amount of lighting required within a tunnel is dependent on the level of ambient lighting at which visual adaptation for the driver is possible on the tunnel approach and inside the tunnel. To achieve this, the lighting of a tunnel is divided into specific zones; the threshold zone and the transition zone are shown in Figure 3. Using the Holladay-Stiles formula, the equivalent veiling luminance $L$ seq can be determined using a graphical method embedded in LiteStar4D software (OxyTech, Milan, Italey), as shown in Figure 4 . The overlay lines and segments are related to the Holladay-Stiles formula [1], which results in a luminance reduction curve and $L_{t h}=178 \mathrm{~cd} / \mathrm{m}^{2}$, as shown in the green curve of Figure 5. In the threshold zone, considering the daylight shining into the tunnel, the minimum average road surface brightness $L_{\mathrm{av}}$ due to tunnel light greater than $105 \mathrm{~cd} / \mathrm{m}^{2}$ is sufficient. Based on CIE 115-1995, the brightness uniformity $U_{\mathrm{o}}$ and the longitudinal brightness uniformity $U_{\mathrm{L}}$ should be higher than 0.4 and 0.6 , respectively; the glare factor $T_{\mathrm{I}}$ needs to be larger than $15 \%$; and the contrast revealing coefficient must be larger than 0.6 for economic reasons.

The criteria of the tunnel lighting design are as follows:

(1) The speed limit of approach $\mathrm{road}=70 \mathrm{~km} / \mathrm{h}$

(2) Stopping distance $=49.4 \mathrm{~m}$

(3) Tunnel Class 2, one-way traffic, motorized only

(4) Traffic flow rate: $500-1000$ vehicles per hour per lane during peak hour

To meet the abovementioned targets, counterbeam lights (CBLs) with one OSRAMVIALOX Nav-T Super $400 \mathrm{~W} /$ 56,500 lumen sodium lamp and linear symmetrical lights

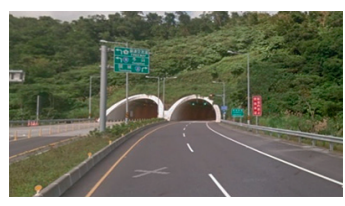

Figure 1: The entrance to the studied tunnel.

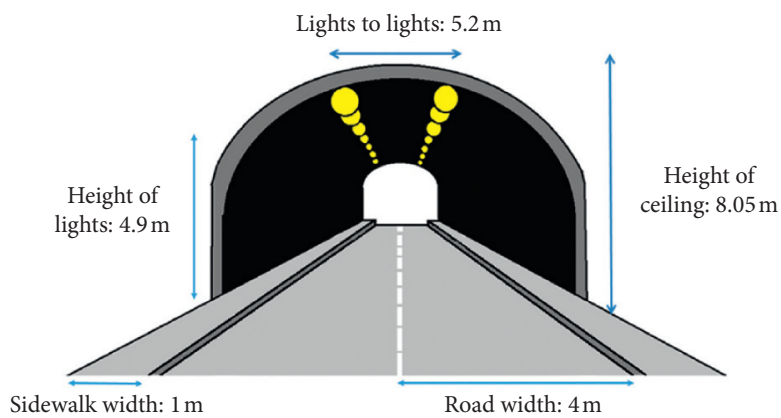

FIgURE 2: The configuration of the trial tunnel geometry.

with two T5 MASTER TL5 HE 35 W/840 SLV/20 fluorescence tubes with efficacy of 94 lumen/W were arranged regularly in the threshold zone. The layout of the lighting design is shown in Figure 6. The spacing of the lights was set to $1.6 \mathrm{~m}$ with one linear light followed by three counterbeam lights in, and then repeating the same arrangement until the end of the zone. For the experiments, the design process of the proposed CBL with sodium lamps is presented. The CBL was prototyped to demonstrate its feasibility for tunnel road lighting for CIE $88: 2004$.

The new CBL is composed of a freeform surfaced reflector and one $400 \mathrm{~W}$ ORSAM high-pressured sodium lamp. With the aim of achieving a contrast revealing coefficient qc higher than 0.6, the new CBL model was built using SolidWorks (DASSAULT SYSTEMES, USA) mechanical software, analyzed using TracePro (Lambda Research, USA) optical software, and optimized with LightTools (Synopsys, USA) software. The design workflow is shown in Figure 7.

During the design process, the optical models of the lamp and reflector were built first, as shown in Figures 8(a) and $8(\mathrm{~b})$, respectively. To determiend the accuracy of the lamp model, the model file was imported into TracePro software for evaluation. Then, we connected the lamp model to the reflector model in TracePro and LightTools as the complete counterbeam light, as shown in Figure 9, to conduct ray tracing analysis and optimization, respectively. The initial reflector model was built, as shown in Figure 10(a), in which surface radii $R_{1}$ and $R_{2}$ were set to 137 and $115 \mathrm{~mm}$, respectively, and the lamp position was set to $(49,-36,100)_{\mathrm{xyz}}$.

Using TracePro, the intensity distribution of the CBL was analyzed, as shown in Figure 10(b), and its far field source file was obtained. However, based on the geometry of the trial tunnel and the criteria of the tunnel lighting design, after importing the source files of CBL and the T5 fluorescence light into LiteStar $4 \mathrm{D}$ for tunnel road lighting 


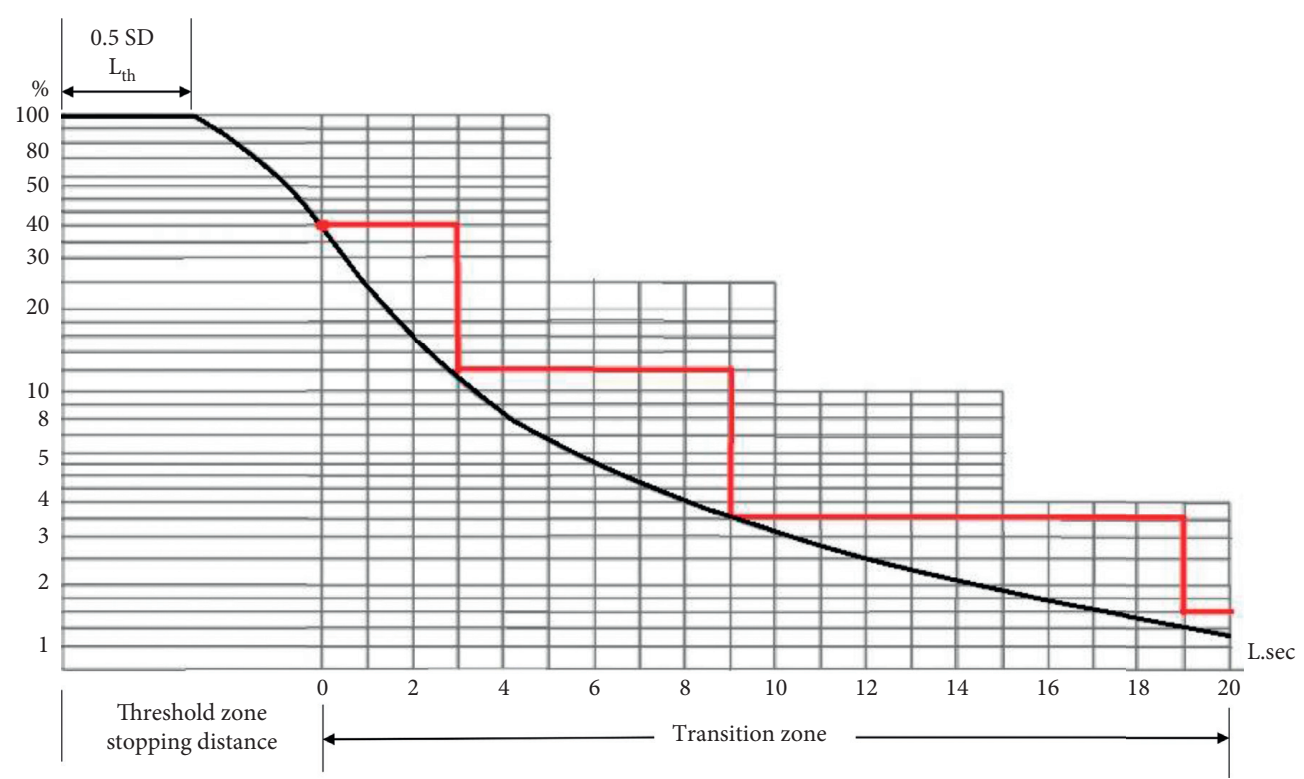

FIGURE 3: The black line is the luminance reduction curve for CIE $88: 2004$ standard. The length of threshold zone $=0.5 \mathrm{SD}$, where $L_{\text {th }}$ is 100 $\%$. Threshold zone length = stopping distance (SD). The red lines indicate the target luminance in the zones of tunnels.

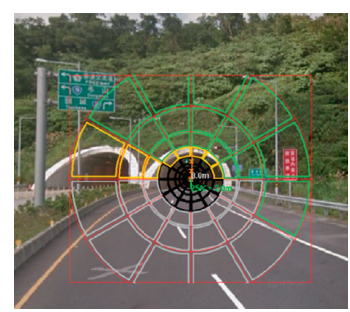

FIGURE 4: $L_{\text {seq }}$ evaluation diagram of the trial tunnel.

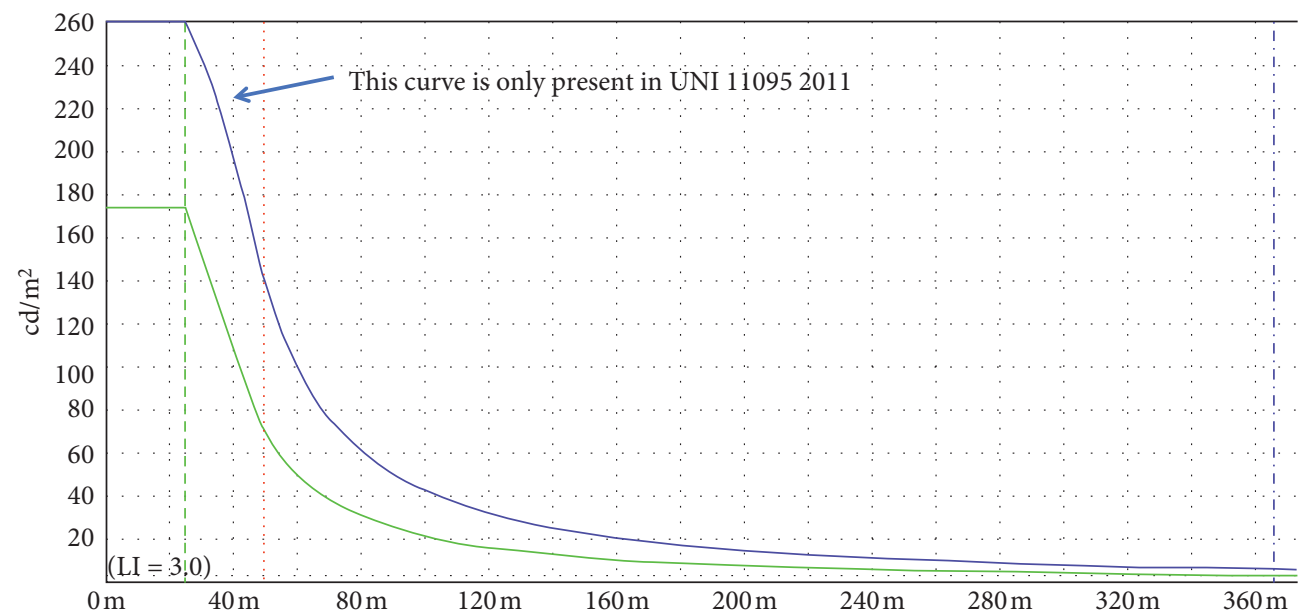

Figure 5: The luminance reduction curve, which indicates the minimum required luminance for accomplishing the standards for the trial tunnel generated by LiteStar 4D software (green curve: CIE 88:2004 standar, blue curve: UNI 11095 .

simulation, the output report showed that its contrast revealing coefficient $q_{\mathrm{c}}$ was 0.24 , which is less than 0.6 . That means that the initially designed $\mathrm{CBL}$ was insufficient. Therefore, the CBL model was optimized using LightTools with the target of a $q_{\mathrm{c}}$ larger than 1.0 in the threshold zone. Through the global searching method with reflector surface radius and lamp position acting as the variables, the CBL was optimized, as shown in Figure 11(a). Its intensity 


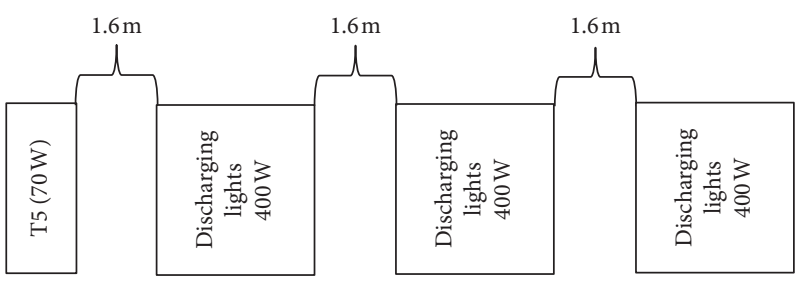

FIgURE 6: The tunnel lighting configuration of one $75 \mathrm{~W}$ T5 fluorescence light followed by three $400 \mathrm{~W}$ discharging lights with sodium lamp for each traffic lane is repeated from the entry to the end of threshold zone.

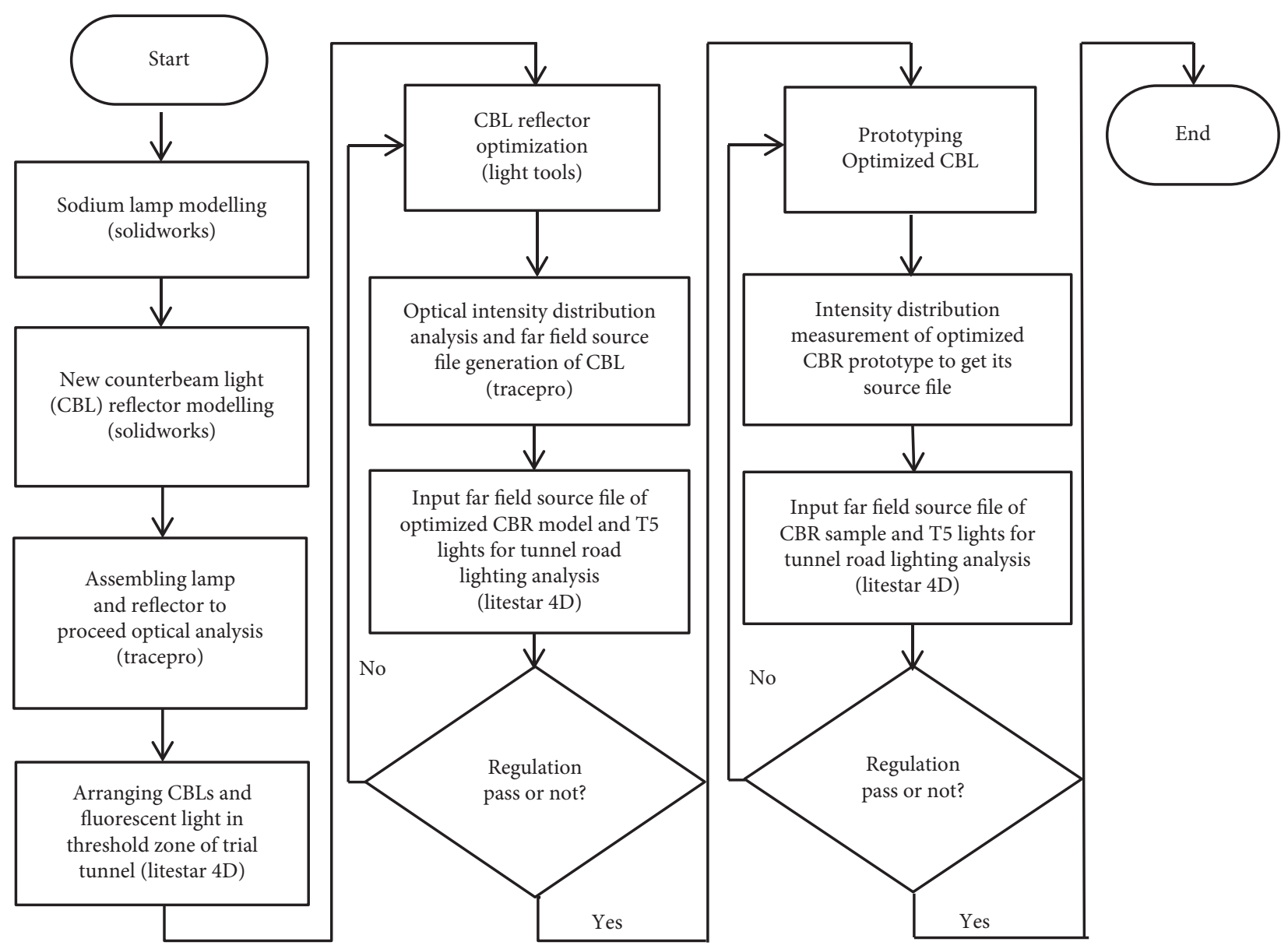

FIgURE 7: The workflow of optimizing counter beam light to accomplish CIE $88: 2004$ tunnel lighting design.

distribution is shown in Figure 11(b). After optimization, the CBL had an $R_{1}$ of $1000 \mathrm{~mm}$ and $R_{2}$ of $85 \mathrm{~mm}$, and the lamp position shifted to $(74,-65,90)_{\mathrm{xyz}}$ from $(49,-36,100)_{\mathrm{xyz}}$. We input the far field source of the optimized CBL into LiteStar $4 \mathrm{D}$; the output report showed that its contrast revealing coefficient $q_{\mathrm{c}}$ was 1.11 , which is above 0.6 , indicating that the new design would qualify as a counterbeam light. The tunnel road lighting performance evaluation items, including average road surface luminance $L_{\mathrm{av}}$, brightness uniformity $U_{\mathrm{o}}$, longitudinal brightness uniformity $U_{\mathrm{L}}$, glare factor $T_{\mathrm{I}}$, and $q_{\mathrm{c}}$ of the initial and final designs of the new CBL are listed in Table 1 for comparison.

To show that the optimized CBL allows the tunnel lighting to meet CIE 88:2004 specifications, a reflector composed of stainless steel was prototyped for optical analysis, as shown in Figure 12. The new CBL fixture installation with the $400 \mathrm{~W}$ sodium lamp with 56,500 lumens is shown in Figure 13, which was measured by imaging goniophotometers (Radiant Imaging Co. Ltd.) to obtain its intensity distribution (Figure 14) and its far field source file, which shows the fixture output power was 37,054 lumens. Therefore, the efficacy was calculated as $37,054 / 400=93$ lumen/W. Therefore, after the source file of the optimized CBL sample was loaded in LiteStar $4 \mathrm{D}$, the output report showed that its $q_{c}$ was $1.19(>0.6)$, which means that the optimized CBL could act as a counterbeam light for tunnel lighting in practice. The tunnel lighting evaluation items, including average road surface luminance $L_{\mathrm{av}}$, brightness 

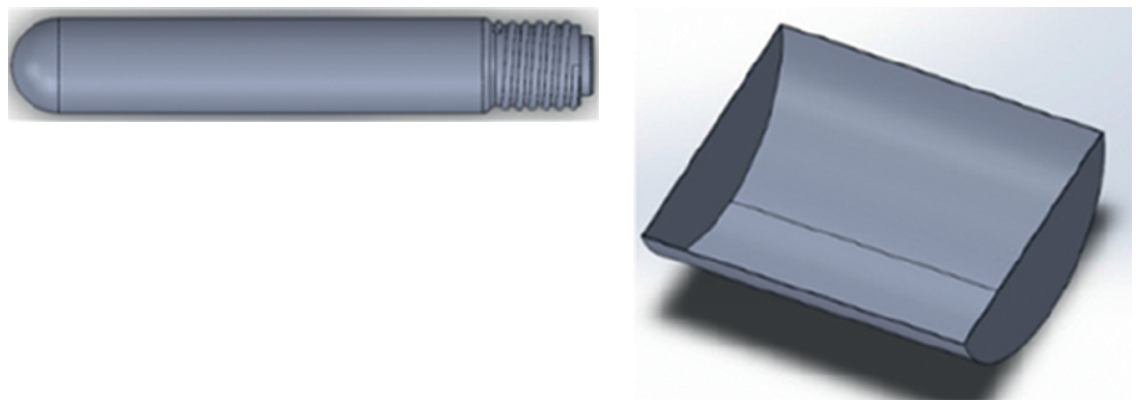

(a)

(b)

FIgUre 8: (a) Model of ORSAM VIALOX NAV-T SUPER 4Y series $400 \mathrm{~W}$ sodium lamp; (b) model of the initial designed reflector of the proposed counterbeam light.

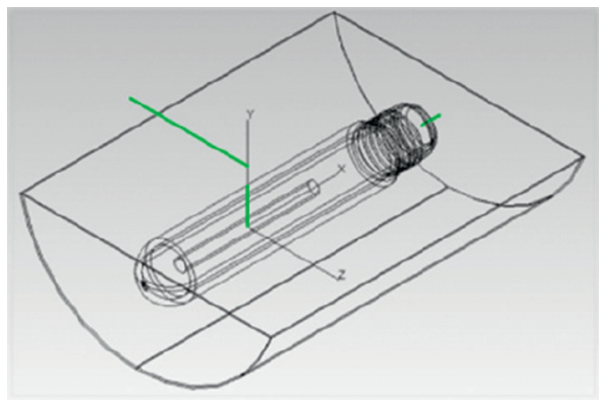

FIGURE 9: The model of the new counterbeam light.

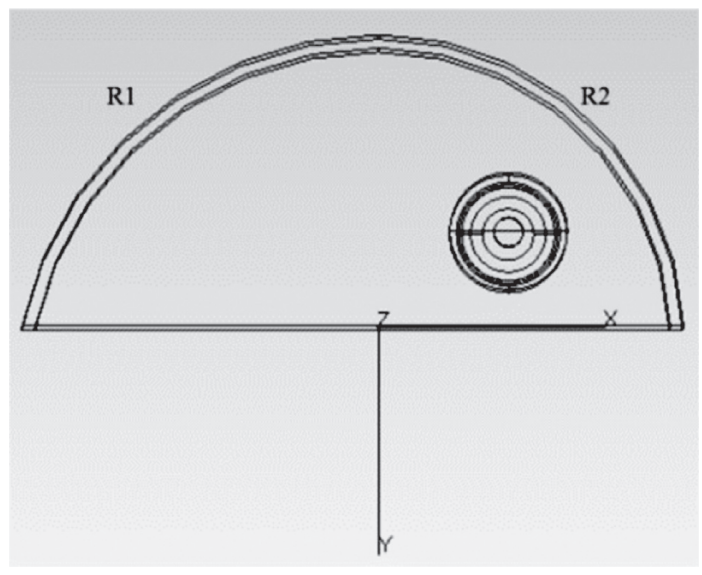

(a)

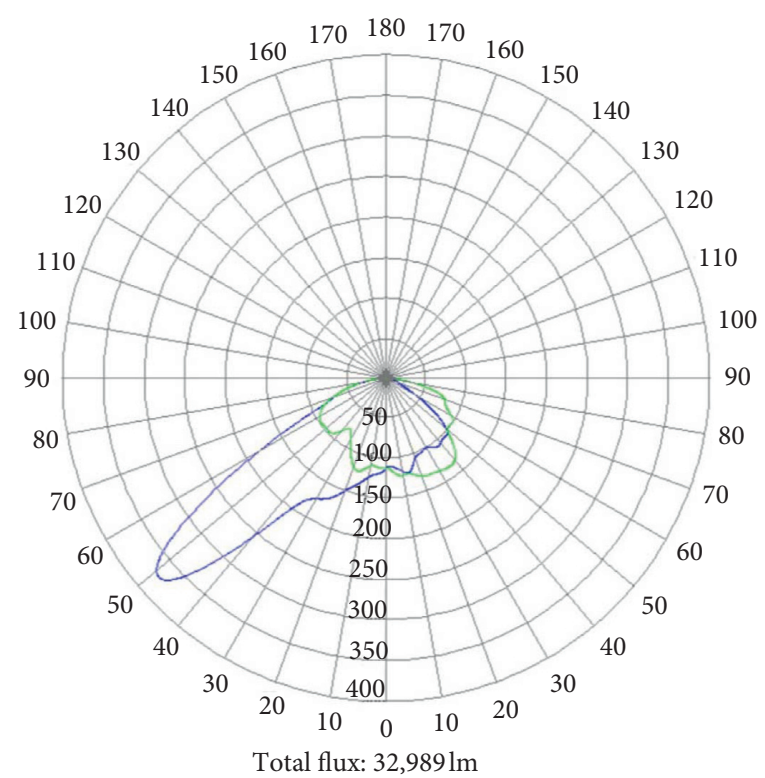

(b)

Figure 10: (a) The side view of the the new counterbeam light before optimization; R1 and R2 are the surface radius of the light. (b) The simulated intensity distribution of the new counterbeam light before optimization.

uniformity $U_{\mathrm{o}}$, longitudinal brightness uniformity $U_{\mathrm{L}}$, glare factor $T_{\mathrm{I}}$, and $q_{\mathrm{c}}$ of the optimized $\mathrm{CBL}$ design and the measurements from the sample are both listed in Table 2 to compare the performance differences.
To demonstrate the advantage of the optimized new CBL, the $400 \mathrm{~W}$ sodium lamp tunnel light GE17734 (General Electric Co., Ltd.), broadly used in tunnels, was used to compare their performance in the threshold zone. The 


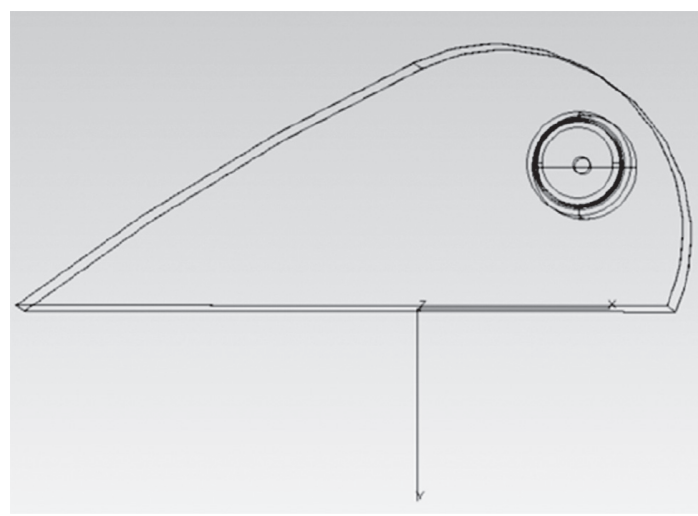

(a)

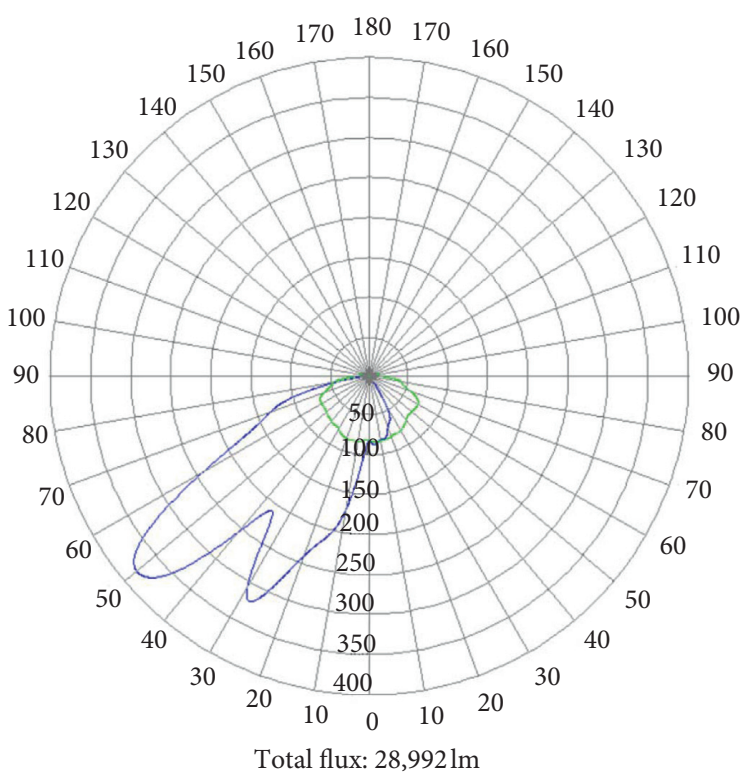

(b)

FIGURE 11: (a) The side view of the new counterbeam light after optimization; (b) the simulated intensity distribution of the optimized CBL with a $400 \mathrm{~W}$ sodium lamp.

TABLe 1: The comparison of lighting performance between the initially designed new CBL and the new optimized CBL for the tunnel threshold zone.

\begin{tabular}{lccc}
\hline Variable & Before optimization & After optimization & $\begin{array}{c}\text { CIE } \\
\text { standard }\end{array}$ \\
\hline$L_{\mathrm{av}}\left(\mathrm{cd} / \mathrm{m}^{2}\right)$ & 121 (pass) & 123 (pass) & $>\mathbf{1 0 5}$ \\
$U_{o}$ & 0.87 (pass) & 0.84 (pass) & $>\mathbf{0 . 4}$ \\
$U_{L}$ & 0.98 (pass) & 0.97 (pass) & $>\mathbf{0 . 6}$ \\
$T_{I}$ & $3.6 \%$ (pass) & $10.41 \%$ (pass) & $<\mathbf{1 5 \%}$ \\
$q_{c}$ & 0.26 (failed) & 1.19 (pass) & $>\mathbf{0 . 6}$ \\
\hline
\end{tabular}

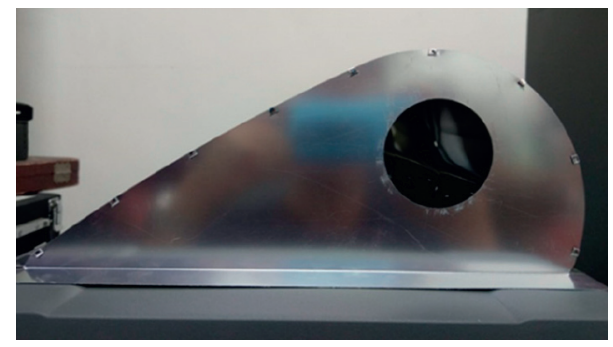

Figure 12: The prototype of the optimized CBL reflector.

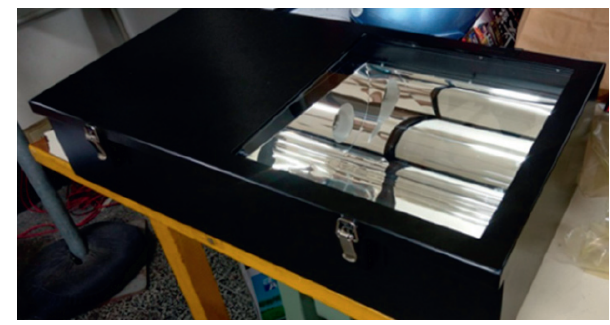

FIgURE 13: The prototype of the optimized CBL light.

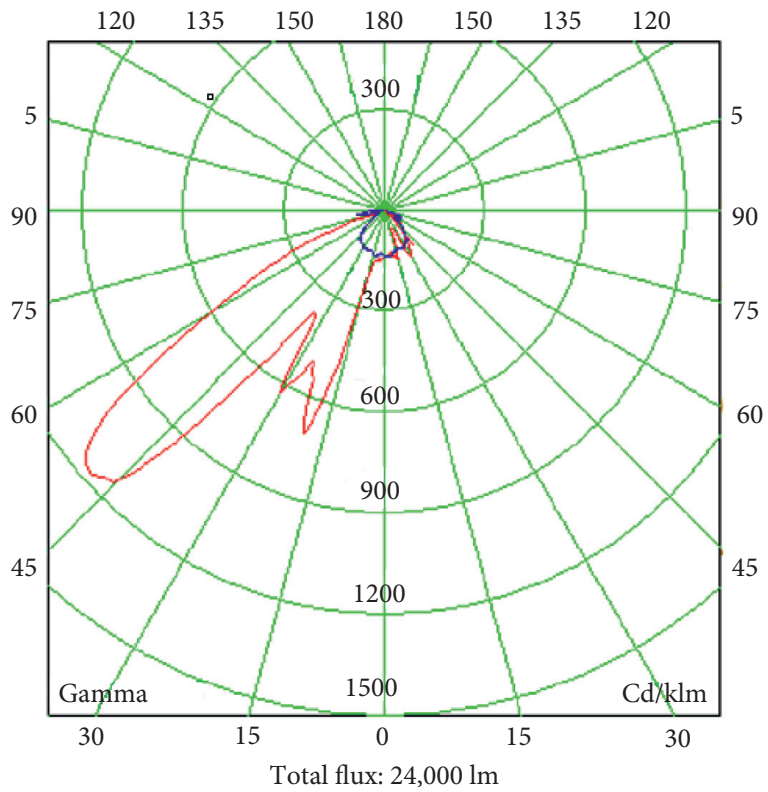

FIgURE 14: The measured intensity distribution of the optimized CBL with the $400 \mathrm{~W}$ sodium lamp.

measured intensity distribution of the GE17734 (General Electric Co., Ltd.) is shown in Figure 15; the output power was 36,865 lumens, and the efficacy was calculated as 36,865 / $400=92$ lumen/W. The lighting performance between the optimized new CBL and the GE17734 (General Electric Co. Ltd.) in threshold zone of tunnel is compared in Table 3. The $q_{\mathrm{c}}$ of GE17734 was 0.55 , which is below the standard and much smaller lower than that (1.08) of the optimized CBL. 
TABLE 2: Comparison of lighting performance between the optimized new CBL design and prototype sample measurements in threshold zone of a tunnel.

\begin{tabular}{lccc}
\hline Variable & $\begin{array}{c}\text { Simulation model of } \\
\text { the optimized new } \\
\text { CBL }\end{array}$ & $\begin{array}{c}\text { Prototyped sample of } \\
\text { the optimized new } \\
\text { CBL }\end{array}$ & $\begin{array}{c}\text { CIE } \\
\text { standard }\end{array}$ \\
\hline$L_{\mathrm{av}}$ & 123 (pass) & 121 (pass) & $>\mathbf{1 0 5}$ \\
$(\mathrm{cd} / \mathrm{m} 2)$ & 0.84 (pass) & 0.88 (pass) & $>\mathbf{0 . 4}$ \\
$U_{o}$ & 0.97 (pass) & 0.98 (pass) & $>\mathbf{0 . 6}$ \\
$U_{L}$ & $10.41 \%$ (pass) & $4.41 \%$ (pass) & $<\mathbf{1 5 \%}$ \\
$T_{I}$ & 1.19 (pass) & 1.08 (pass) & $>\mathbf{0 . 6}$ \\
$q_{c}$ & &
\end{tabular}

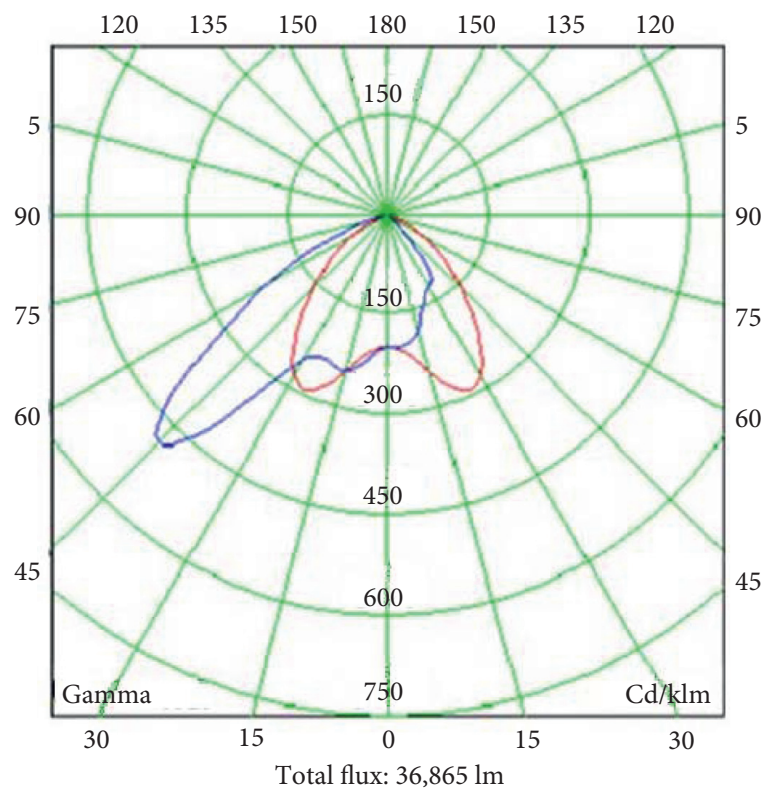

FIgURE 15: The measured intensity distribution of the GE17734 CBL (General Electric Co. Ltd.) with the $400 \mathrm{~W}$ sodium lamp.

TABLE 3: Comparison of the lighting performance between the GE17734 sodium tunnel light and the optimized new CBL.

\begin{tabular}{lccc}
\hline Parameter & $\begin{array}{c}\text { GE17734 } \\
\text { sodium tunnel } \\
\text { light }\end{array}$ & $\begin{array}{c}\text { Prototyped sample of } \\
\text { the optimized new CBL }\end{array}$ & $\begin{array}{c}\text { CIE } \\
\text { standard }\end{array}$ \\
\hline$L_{\mathrm{av}}$ & 139 (pass) & 121 (pass) & $>\mathbf{1 0 5}$ \\
$(\mathrm{cd} / \mathrm{m} 2)$ & 0.82 (pass) & 0.88 (pass) & $>\mathbf{0 . 4}$ \\
$U_{o}$ & 0.98 (pass) & 0.98 (pass) & $>\mathbf{0 . 6}$ \\
$U_{L}$ & $1.55 \%$ (pass) & $4.41 \%$ (pass) & $<\mathbf{1 5 \%}$ \\
$T_{I}$ & 0.55 (failed) & 1.08 (pass) & $>\mathbf{0 . 6}$ \\
$q_{c}$ &
\end{tabular}

\section{Discussion and Conclusions}

To improve driving safety, a new counterbeam light (CBL) was proposed to meet CIE $88: 2004$ regulations for tunnel lighting. Using appropriate arrangements of the counterbeam light and conventional fluorescent lights on the ceiling of a tunnel, we demonstrated that road tunnel lighting with CIE $88: 2004$ regulations can be accomplished in the LiteStar $4 \mathrm{D}$ simulation environment. Based on the simulated physical source model, the new counterbeam can produce an average road surface brightness of $123 \mathrm{~cd} / \mathrm{m}^{2}$ (minimum regulation level $=105 \mathrm{~cd} / \mathrm{m}^{2}$ ), a brightness uniformity $U_{\mathrm{o}}$ of 0.84 (minimum regulation level $=0.4$ ), a longitudinal brightness uniformity $U_{\mathrm{L}}$ of 0.97 (minimum regulation level=0.6), a glare factor $T_{\mathrm{I}}$ of $10.41 \%$ (maximum lev$\mathrm{el}=15 \%)$, and a contrast revealing coefficient $q_{\mathrm{c}}$ of 1.19 (minimum level $=0.6$ ) in the threshold zone. For demonstrating the feasibility of the new CBL in tunnels, a prototype was constructed and measured using an imaging goniophotometer. Based on LiteStar 4D simulation, the source file created through the measurement of the new CBL sample achieved an average road surface brightness $L_{\mathrm{av}}$ of $121 \mathrm{~cd} / \mathrm{m}^{2}$ ( minimum regulation level $=105 \mathrm{~cd} / \mathrm{m}^{2}$ ), a brightness uniformity $U_{\mathrm{o}}$ of 0.88 (minimum regulation level $=0.4$ ), a longitudinal brightness uniformity $U_{\mathrm{L}}$ of 0.98 (minimum regulation level $=0.6$ ), a glare factor $T_{\mathrm{I}}$ of $4.41 \%$ (maximum level $=15 \%$ ), and a contrast revealing coefficient $q_{\mathrm{c}}$ of 1.08 (minimum level $=0.6$ ) in the threshold zone. As a result, we concluded that the proposed CBL can act as a qualified counterbeam light to help tunnel road lighting meet CIE 88 : 2004 standards both in simulation and in practice.

We compared the performance of the GE17734 tunnel light and the new CBL before and after optimization. The experimental results (Tables 1-3) showed that the road luminance produced by the optimized new CBL is the lowest but has the highest $q_{\mathrm{c}}$, which means cars, people, or other objects observed on road are the most contrasted, revealed by the optimized CBL. The results shown in Figures 15, $10(\mathrm{~b})$, and 11(b) show that the optimized new CBL has a weaker light intensity at $40^{\circ}-45^{\circ}$, meaning light dominates the road luminance of drivers, so the optimized new CBL cannot provide as much luminance as the other fixtures.[20]

\section{Data Availability}

No data were used to support this study.

\section{Conflicts of Interest}

The authors declare that they have no conflicts of interest.

\section{Authors' Contributions}

The authors contributed equally to all parts of this study.

\section{References}

[1] R. H. Simons and A. R. Bean, Lighting Engineering: Applied Calculations, Routledge, Abingdon, UK, 2008.

[2] J. A. Vrooman, Crossing the Threshold: Nabi Depictions of Masculinity in Public, Private, and Performative Spaces of FinDe-SiècleParis, Dissertation, New York University, New York, NY, USA, 2017.

[3] M. Rea, J. Bullough, and Y. Akashi, "Several views of metal halide and high-pressure sodium lighting for outdoor applications," Lighting Research \& Technology, vol. 41, no. 4, pp. 297-320, 2009.

[4] M. S. Rea, A. Bierman, T. McGowan, F. Dickey, and J. A. Havard, "Eld study comparing the eCEectiveness of metal halide and highpressure sodium illuminants under mesopic 
conditions," in Proceedings of the Visual Scales: Photometric and Colorimetric Aspects, London, UK, March 1997.

[5] Guide for the Lighting of Road Tunnels and Underpasses, 2nd EdCIE 088-1990, 1990.

[6] J. Da Silva FM, H. M. Bártolo, P Bártolo et al., Challenges for Technology Innovation: An Agenda for the Future: Proceedings of the International Conference on Sustainable Smart Manufacturing (S2M 2016), CRC Press, Lisbon, Portugal, 2017.

[7] J. E. M. Teoh, C. K. Chua, Y. Liu, and J. An, "4D printing of customised smart sunshade: a conceptual study," Challenges for Technology Innovation: An Agenda for the Future, vol. 105, no. 108, pp. 105-108, 2017.

[8] P. R. Boyce, N. H. Eklund, B. J. Hamilton, and L. D. Bruno, "Perceptions of safety at night in different lighting conditions," Lighting Research and Technology, vol. 32, no. 2, pp. 79-91, 2000.

[9] W. V. Bommel, Road Lighting: Fundamentals, Technology and Application, Springer, Berlin, Germany, 2014.

[10] S. W. Smith and M. S. Rea, "Relationships between office task performance and ratings of feelings and task evaluations under different light sources and levels," in Proceedings of the19th Session of Commission Internationale de l'Éclairage,Kyoto, Japan, 1980.

[11] Y. Akashi, M. S. Rea, and J. D. Bullough, "Driver decision making in response to peripheral moving targets under mesopic light levels," Lighting Research \& Technology, vol. 39, no. 1, pp. 53-67, 2007.

[12] Z. Feng, Y. Luo, and Y. Han, "Design of LED freeform optical system for road lighting with high luminance/illuminance ratio," Optics Express, vol. 18, no. 21, pp. 22020-22031, 2010.

[13] Commission Internationale de l'Éclairage, Lighting of Roads for Motor and Pedestrian Traffic: CIE 115, CIE, Peter Blattner; Switzerland, 2010.

[14] C. Knight, "Field surveys of the effect of lamp spectrum on the perception of safety and comfort at night," Lighting Research \& Technology, vol. 42, no. 3, pp. 313-329, 2010.

[15] S. Fotios and R. Gibbons, "Road lighting research for drivers and pedestrians: the basis of luminance and illuminance recommendations," Lighting Research \& Technology, vol. 50, no. 1, pp. 154-186, 2018.

[16] A. Scott, "White light-the UK balance sheet," Lighting Journal, vol. 70, no. 1, 2005.

[17] S. Hecht, C. Haig, and A. M. Chase, "The influence of light adaptation on subsequent dark adaptation of the eye," The Journal of General Physiology, vol. 20, no. 6, pp. 831-850, 1937.

[18] B. Ahmed, Road Lighting, 2017.

[19] P. R. Boyce, Lighting for Driving: Roads, Vehicles, Signs, and Signals, CRC Press, Boca Raton, FL, USA, 2008.

[20] P. R. Boyce and L. D. Bruno, "An evaluation of high pressure sodium and metal halide light sources for parking lot lighting," Journal of the Illuminating Engineering Society, vol. 28, no. 2, pp. 16-32, 1999. 